\title{
A versatile salicylic acid precursor method for preparing titanate microspheres
}

\author{
Wei Liu, Yang Qu, Wei Zhou, Zhiyu Ren, Baojiang Jiang, Guofeng Wang, Le Jiang, \\ Fulong Yuan* and Honggang $\mathrm{Fu}^{1 *}$
}

\begin{abstract}
Mixed-phase $\mathrm{MgTiO}_{3} / \mathrm{MgTi}_{2} \mathrm{O}_{5}$ microspheres were prepared through a salicylic acid precursor method and further calcined in air. The microspheres were formed through coordination, polymerization, and aggregation processes. Salicylic acid acted as a ligand in coordinating with metal ions, in addition to acting as a structure-directing agent in the polymerization and aggregation of the titanate precursor microspheres via chemical bonds and electrostatic attraction. The mixed-phase $\mathrm{MgTiO}_{3} /$ $\mathrm{MgTi}_{2} \mathrm{O}_{5}$ microspheres prepared by this method showed excellent photocatalytic hydrogen production efficiencies that were two and four times higher than mixed-phase nanoparticles and pure-phase nanoparticles, respectively, owing to their closed phase junctions and sphere-like morphologies. This versatile and facile salicylic acid precursor method was also used to prepare a number of other bivalent metal-based titanate microspheres, including $\mathrm{BaTiO}_{3}, \mathrm{ZnTiO}_{3}, \mathrm{CoTiO}_{3}, \mathrm{NiTiO}_{3}$, and $\mathrm{CdTiO}_{3}$.
\end{abstract}

\section{INTRODUCTION}

$\mathrm{ATiO}_{3}$-type (where $\mathrm{A}$ is a bivalent metal ion) perovskite titanates are key materials used in electronic devices, ceramics, solid oxide fuel cell electrodes, metal-air barriers, and gas sensors, owing to their outstanding electrical properties, chemical stability, and excellent dielectric loss constant [1-5]. Although these materials have been used for over 50 years, some unusual characteristics related to their photocatalytic properties have recently been discovered, which might lead to new applications in photoelectrochemistry and water splitting [6-8]. However, the limitations in material synthesis techniques and the lack of clear understanding of their electron structures hinder the exploitation of the full potential of titanates. Therefore, it is vital to develop new strategies for preparing highly efficient and functional nano-titanates and further study their electronic structures. Controlling the morphology of titanates is particularly important.

Microsphere-based functional materials have attracted great interest because of their potential for applications in a wide range of areas, such as drug delivery, photocataly- sis, dye-sensitized solar cells, gas sensors, and lithium-ion batteries, as a result of their intrinsic optical properties, high surface area, low density, and anisotropy [9]. Inverse opalphotonic crystals assembled from microspheres are regarded as a bridge connecting artificial and natural materials. Such materials are utilized in chemical sensing, solar cells, and biosensing [10-12] applications. Microspherical materials have been demonstrated as key materials in energy and environment applications. Although a number of metal oxide microspheres have been prepared by various approaches such as hydrothermal techniques [13], Ostwald ripening [14], and solvothermal techniques [15], there are few reports on titanate microspheres, which may be due to the lack of availability of suitable synthesis methods. Conventional solid-state reactions that are used to prepare titanates usually yield products with large particle size, large amounts of impurities, and irregular morphologies. In addition, such reactions also require high sintering temperatures $\left(>1000^{\circ} \mathrm{C}\right)$ and long reaction times $(>6 \mathrm{~h})[16,17]$. Therefore, developing new synthesis strategies for titanate microspheres with low energy consumption, controlled reactions, and ease of use is a great challenge.

Coordination chemistry is among the most important branches of chemistry. Many functional materials such as metal-organic frameworks, dyes, and metal-based molecules have been synthesized based on the principles of coordination chemistry. By utilizing metal ions and ligands, it is easy to obtain a soft precursor for metal oxides or perovskites. The metal-ligand precursor formed by the coordination polymerization of metal acetate and an organic ligand is a natural soft source for metal oxides and titanates, because the metal-oxygen octahedral bridge formed by the cross-linking of metal ions and oxygen, can easily transform into metal-oxide units during calcination $[18,19]$. These soft metal-organic precursors could easily transform into titanates after annealing in air and the microsphere shape could be retained. The metal-ligand precursor route can significantly reduce the sintering temperature and reaction time to about $600^{\circ} \mathrm{C}$ and $2 \mathrm{~h}$, respectively, owing

Key Laboratory of Functional Inorganic Material Chemistry, Ministry of Education of China, Heilongjiang University, Harbin 150080, China "Corresponding authors (emails: fuhg@vip.sina.com (Fu H); yflhlj@163.com (Yuan F)) 
to the soft structure of the precursors [20]. However, the metal-ligand precursor method is restricted by ionic radius and other parameters. Therefore, a new and versatile method for preparing functional titanates is required.

In this context, we report a versatile method based on the salicylic acid (SA) medium for preparing $\mathrm{ATiO}_{3}$ (where $\mathrm{A}=\mathrm{Mg}, \mathrm{Ba}, \mathrm{Zn}, \mathrm{Co}, \mathrm{Ni}$, and $\mathrm{Cd}$ ) microspheres. Through this method, sphere-like titanates could be obtained by using SA as a ligand. The metal-SA frameworks can be assembled through the conjugated $\pi-\pi$ interactions of the benzene ring in SA and the hydrogen bond as described in the literature [21]. Mixed-phase magnesium titanates ( $\mathrm{Mg}$ $\mathrm{TiO}_{3} / \mathrm{MgTi}_{2} \mathrm{O}_{5}$ ) are believed to be excellent photocatalysts for hydrogen production, owing to the natural phase junctions formed by the mixed-phase $\mathrm{MgTiO}_{3}$ and $\mathrm{MgTi}_{2} \mathrm{O}_{5}$ that could enhance charge separation [22].

\section{EXPERIMENTAL SECTION}

\section{Synthesis}

The typical synthesis procedure for titanate microspheres using the SA precursor method was as follows. Clear ethanol solution $(40 \mathrm{~mL})$ containing $0.01 \mathrm{~mol}$ of metal acetate $(\mathrm{Mg}, \mathrm{Ba}, \mathrm{Zn}, \mathrm{Co}, \mathrm{Ni}$, and $\mathrm{Cd}), 0.01 \mathrm{~mol}$ of tetrabutyl titanate, and $0.01 \mathrm{~mol}$ of SA was transferred into a $50 \mathrm{~mL}$ Teflon-lined stainless-steel autoclave, which was then sealed and heated at $180^{\circ} \mathrm{C}$ for $12 \mathrm{~h}$. After the solvothermal reaction, a precipitate containing the metal-SA precursor was obtained. The precursor was purified using three centrifugation and redispersion cycles with absolute ethanol and was dried under vacuum at $60^{\circ} \mathrm{C}$ for $4 \mathrm{~h}$. The titanate microspheres were prepared by calcining the precursor in air at different temperatures for $2 \mathrm{~h}$. The mixed-phase magnesium titanate samples were used for photocatalytic hydrogen production and were denoted as MT600, MT700, and MT800 for easy identification.

\section{Characterization}

X-ray powder diffraction (XRD) patterns were obtained using the Bruker D8XRD unit. Scanning electron microscopy (SEM) images were acquired using a Hitachi S-4800 instrument operating at $15 \mathrm{kV}$. Transmission electron microscopy (TEM) experiments were performed on a JEM-2100 electron microscope (JEOL, Japan) with an acceleration voltage of $200 \mathrm{kV}$. Carbon-coated copper grids were used as the sample holders. Pyrolysis of the metal-SA precursors was carried out in a thermogravimetry (TG) unit (TA, Q600) under a stream of air with a heating rate of $10^{\circ} \mathrm{C} \mathrm{min}-1$. The specific surface area of the product was determined using the Brunauer-Emmett-Teller (BET) method using a Tristar II 3020 surface area and porosity analyzer (Micromeritics). UV-visible absorption spectra were recorded using a UV-visible spectrophotometer (SHIMADZU UV-2550).

\section{Photocatalysis}

The photocatalytic hydrogen production experiments were conducted in an online photocatalytic hydrogen production system (AuLight, Beijing, CEL-SPH2N) at ambient temperature $\left(20^{\circ} \mathrm{C}\right)$. The catalyst $(0.1 \mathrm{~g})$ was suspended in a mixture of distilled water $(80 \mathrm{~mL})$ and methanol $(20 \mathrm{~mL})$ in the reaction cell using a magnetic stirrer. Pt-loaded photocatalysts (1 wt.\%) were prepared by a known standard in-situ photodeposition method using $\mathrm{H}_{2} \mathrm{PtCl}_{6}$ aqueous solution. Prior to the reaction, the mixture was deaerated by evacuation to remove the $\mathrm{O}_{2}$ and $\mathrm{CO}_{2}$ dissolved in water. The reaction was carried out by irradiating the mixture with UV light from a $300 \mathrm{~W}$ Xe lamp (AuLight, CELHXF300) with a UVREF filter (AuLight, 200-400 nm). Gas evolution was observed only under photoirradiation and the evolved gases were analyzed using an online gas chromatograph (SP7800, TCD, molecular sieve $5 \AA, \mathrm{N}_{2}$ carrier, Beijing Keruida Limited).

The apparent quantum efficiency (AQE) for hydrogen generation was determined using the same closed circulating system with a $300 \mathrm{~W}$ Xe lamp and band pass filter (313 $\mathrm{nm}$ ) illumination system. The light intensity was measured using a Si photodiode (Oreal 91105V). The total light intensity was $11.3 \mathrm{~mW} \mathrm{~s}^{-1}$ at $313 \mathrm{~nm}$ and the irradiation area was around $7 \mathrm{~cm}^{2}$. The AQE values at different wavelengths were calculated using the following equation [23]:

$$
\mathrm{AQE}=\frac{2 \times \text { the number of evolved } \mathrm{H}_{2} \text { molecules }}{\text { the number of incident photons }} \times 100 \% \text {. }
$$

\section{RESULTS AND DISCUSSION}

In this work, mixed-phase $\mathrm{MgTiO}_{3} / \mathrm{MgTi}_{2} \mathrm{O}_{5}$ and other metal titanate microspheres were prepared by the SA precursor method. Magnesium titanate is different from the othermetal titanates, since it exists in two phases $\left(\mathrm{MgTiO}_{3}\right.$ and $\mathrm{MgTi}_{2} \mathrm{O}_{5}$ ), as a result of which it is very difficult to obtain a pure phase. However, we found that the mixed-phase is beneficial for photocatalysis [22]. The SEM images of the Mg-SA precursor shown in Fig. 1 reveal that the precursor exhibits sphere-like morphology with a diameter of about 4-5 $\mu \mathrm{m}$. The high-resolution SEM images in Figs $1 \mathrm{~b}$ and $\mathrm{c}$ clearly show that the surface of the microspheres is rough, indicating that the microspheres are formed by the aggregation of small nanoparticles that are about $10-30 \mathrm{~nm}$ in diameter. This implies that the polymerization of $\mathrm{Mg}-\mathrm{SA}$ complexes occurs via chemical contact and aggregation through self-assembly of the small nanoparticles. The XRD pattern of the precursor, which is shown in Fig. 1d, further indicates the presence of the metal framework. It is well accepted that the XRD peak at $2 \theta$ of around $10^{\circ}$ can be at- 

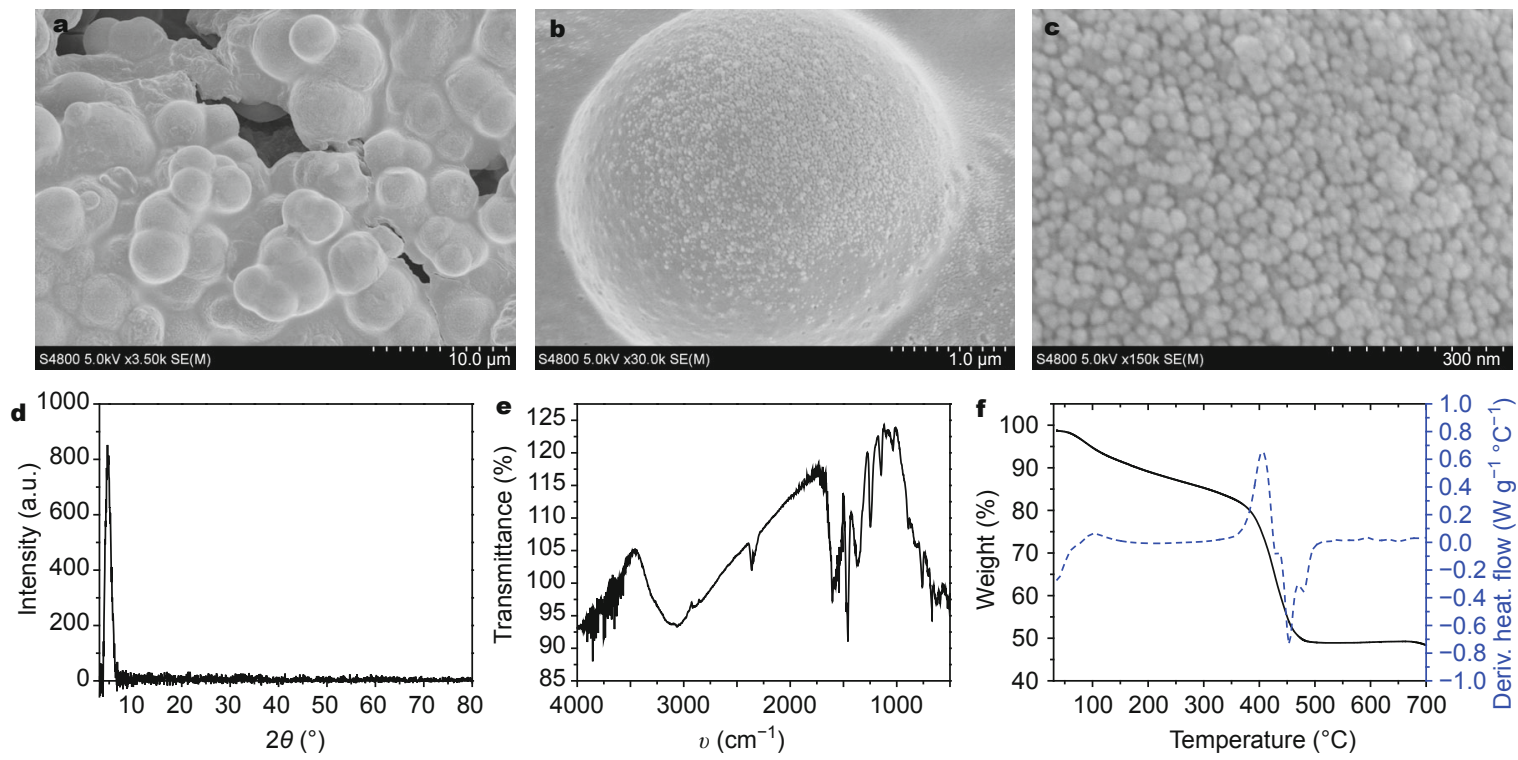

Figure 1 (a, b and c) SEM images at different resolutions, (d) XRD pattern, (e) FT-IR spectrum, and (f) TG curve of Mg-SA microsphere precursor.

tributed to the typical metal framework formed by $\mathrm{Mg}^{2+}$ and SA [24]. The Fourier transform infrared (FT-IR) spectrum of the Mg-SA precursor (Fig. 1e) shows the presence of organic groups including carboxyl and hydroxyl groups (indicated by the peak at $3300 \mathrm{~cm}^{-1}$ ) and benzene ring (peaks at $1620,1490,1384$, and $\left.1252 \mathrm{~cm}^{-1}\right)$. In addition, peaks are observed at 1119 and $779 \mathrm{~cm}^{-1}$, which are attributed to the $\mathrm{C}-\mathrm{O}$ vibration and orthosubstituent benzene, respectively. The above data illustrate that the microspheres are formed by the polymerization of Mg-SA complexes.

The TG curve shown in Fig. If demonstrates that the metal-organic framework consists of about $51 \%$ organic species, implying that one metal ion could coordinate with two SA molecules, based on their molecular weight. Based on these results, we believe that the magnesium titanate microspheres were formed by the coordination-polymerization-aggregation-calcination process illustrated in Scheme 1.

During the solvothermal reaction, the anion is a linear trinuclear carboxylate cluster with octahedral $\mathrm{Mg}^{2+}$ ions bridged by four $\mathrm{SA}^{-}$ions and two $\mu^{2}$-bridging water molecules. Four $\mathrm{SA}^{-}$bind to the two terminal $\mathrm{Mg}^{2+}$ ions as monodentate ligands and form hydrogen bonds with the $\mu^{2}$-bridging water molecules, completing the $\mathrm{Mg}-\mathrm{SA}-\mathrm{H}_{2} \mathrm{O}$ networks, as reported in the literature [25-27]. The networks then begin to polymerize and aggregate into spherelike structures, which have minimum surface energy. SEM images acquired over the course of the reaction (Fig. S1) further prove that the microspheres are formed by the self-assemblyof small nanoparticles.

The SEM images of the mixed-phase $\mathrm{MgTiO}_{3} / \mathrm{MgTi}_{2} \mathrm{O}_{5}$

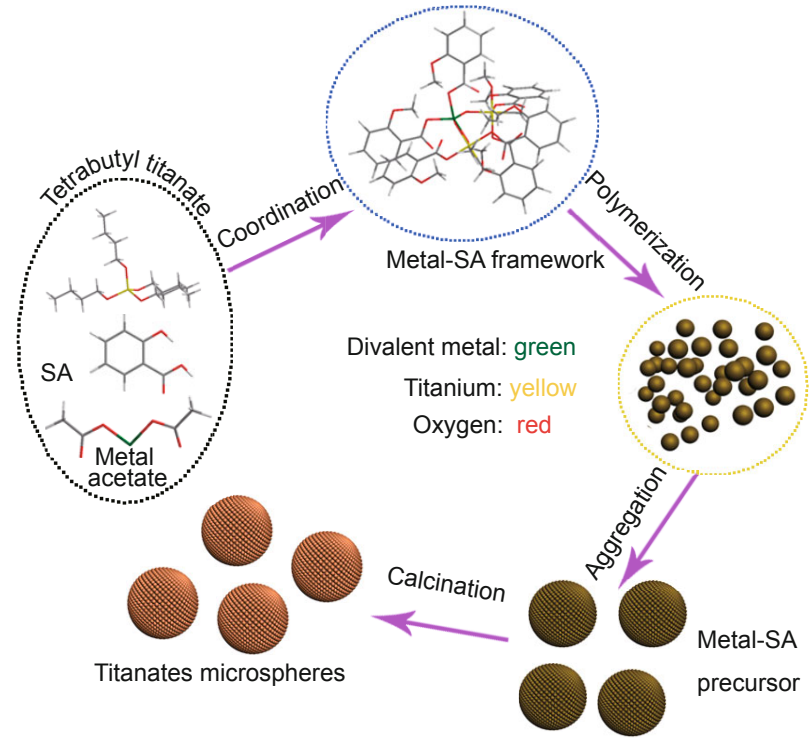

Scheme 1 Formation of the titanate microspheres via the salicylic acid precursor method.

microspheres after calcination at different temperatures from 600 to $800^{\circ} \mathrm{C}$, are shown in Fig. 2. The annealing temperature is crucial in the case of mixed-phase magnesium titanate, since the phase transformations that occur during annealing at various temperatures cause different behavior of the photogenerated charges. In the low-resolution SEM image of MT700, it is clear that the surface of the microspheres is smooth and the microspheres are uniform and monodispersed. In the cases of MT600 and MT800, there are no obvious differences in the SEM images (Figs 2a, e, 

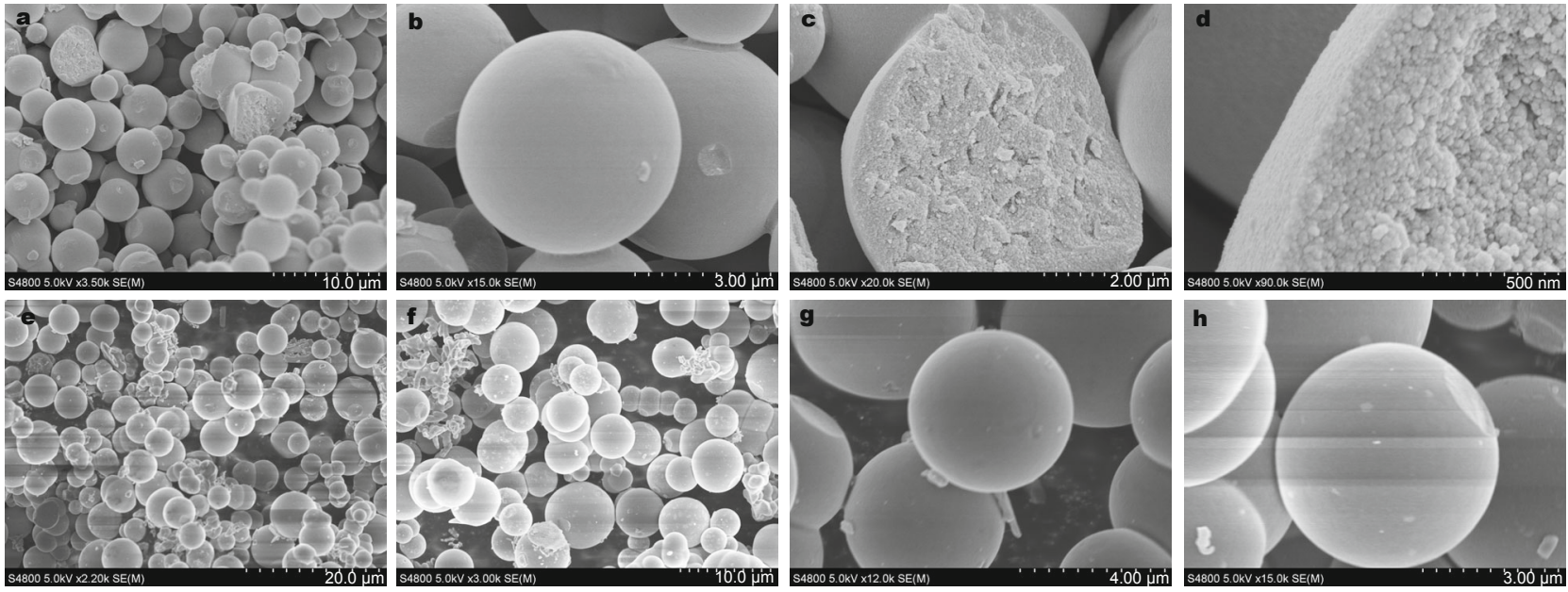

Figure 2 SEM images of mixed-phase $\mathrm{MgTiO}_{3} / \mathrm{MgTi}_{2} \mathrm{O}_{5}$ microspheres annealed at different temperatures:(a, b, c, and d) MT700, (e, g) MT600, and $(f, h)$ MT800. $g$ and $h$ are high-resolution images of e and $f$.

$\mathrm{f}, \mathrm{g}$ and $\mathrm{h})$. The high-resolution SEM images of the broken sphere shown in Figs $2 \mathrm{c}$ and $\mathrm{d}$ indicate that the spheres are solid and are aggregates of small nanoparticles that are about $10-20 \mathrm{~nm}$ in size and in close contact with each other.

In order to confirm the effect of annealing temperature on the phase transformations of titanates, the Mg-SA precursor samples were annealed at three different temperatures and the phases of the three samples were analyzed using XRD. Two different phases of magnesium titanates are observed in the XRD patterns (Fig. 3), namely $\mathrm{MgTiO}_{3}$ with a rhombohedral (hexagonal) structure and $\mathrm{MgTi}_{2} \mathrm{O}_{5}$ with a base-centered orthorhombic structure. XRD peaks are observed at $2 \theta$ values of $19.2^{\circ}, 21.1^{\circ}, 23.9^{\circ}, 35.5^{\circ}, 40.6^{\circ}$, $49.2^{\circ}, 53.6^{\circ}, 56.94^{\circ}, 62.2^{\circ}, 63.8^{\circ}, 71.3^{\circ}$, and $75.2^{\circ}$, which can be attributed to the (003), (101), (012), (104), (110), (113),

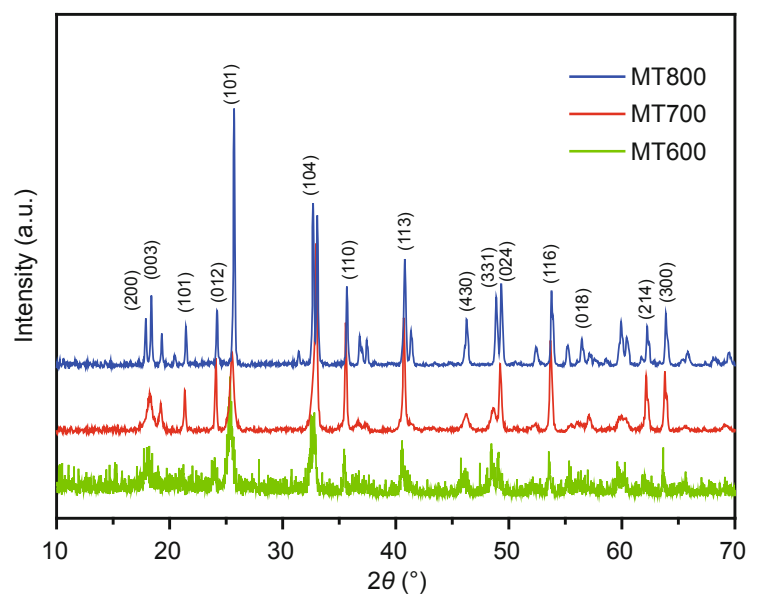

Figure 3 XRD patterns of MT600, MT700, and MT800. Red colored crystalline plane designations correspond to $\mathrm{MgTi}_{2} \mathrm{O}_{5}$, whereas black color designations denote $\mathrm{MgTiO}_{3}$.
(024), (116), (018), (214), (300), (303), and (208) reflections of rhombohedral $\mathrm{MgTiO}_{3}$ (JCPDS no. 06-0494). Additionally, the peaks at $18.12^{\circ}, 25.4^{\circ}, 46.4^{\circ}$, and $48.6^{\circ}$ agree well with the known peak positions for the (200), (101), (430), and (331) reflections of base-centered orthorhombic structure of $\mathrm{MgTi}_{2} \mathrm{O}_{5}$ (JCPDS no. 35-0792). It can be seen that at thecalcination temperature of $600^{\circ} \mathrm{C}$, the orthorhombic $\mathrm{MgTi}_{2} \mathrm{O}_{5}$ phase is weak and the peak corresponding to the (200) plane is not obvious, implying that higher temperatures are required for forming $\mathrm{MgTi}_{2} \mathrm{O}_{5}$. The XPS results shown in Fig. S2 indicate that the ratios between $\mathrm{MgTiO}_{3}$ and $\mathrm{MgTi}_{2} \mathrm{O}_{5}$ in the mixed-phase junctions are not affected by the chemical environment of $\mathrm{Mg}$ and $\mathrm{Ti}$.

TEM images were used to further understand the structure of the solid mixed-phase microspheres. Fig. $4 \mathrm{~b}$ indicates that the constituent nanoparticles in the microspheres are about $10-30 \mathrm{~nm}$, which is consistent with the obser-

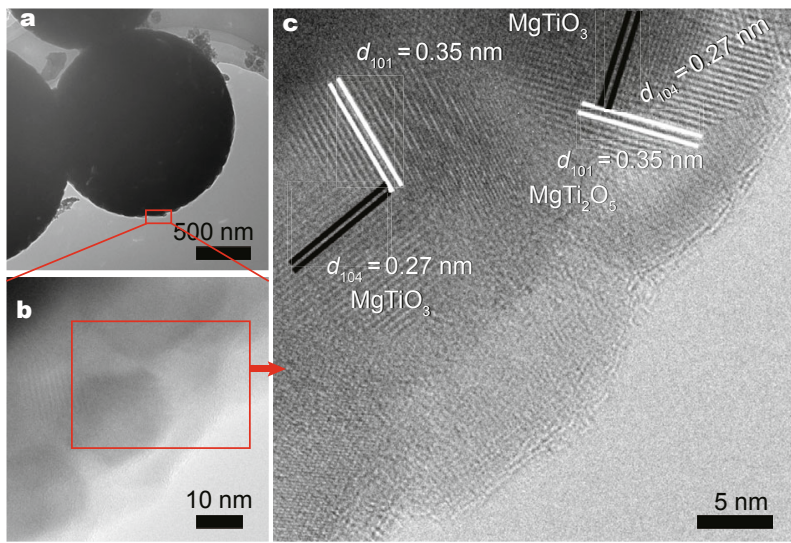

Figure 4 (a, b) TEM images and (c) high-resolution TEM image of MT700. 
vations from the SEM images. The heterogeneous (104) phase junction of $\mathrm{MgTiO}_{3}$ with an interplanar spacing of $0.27 \mathrm{~nm}$ and (101) phase junction of $\mathrm{MgTi}_{2} \mathrm{O}_{5}$ with an interplanar spacing of $0.35 \mathrm{~nm}$ are also observed from thehigh-resolution TEM images in Fig. 4c. This mixed-phase junction consisting of $\mathrm{MgTiO}_{3} / \mathrm{MgTi}_{2} \mathrm{O}_{5}$ has been proven to have excellent charge separation capabilities because of the heterophase junctions, making it a potential catalyst for photocatalysis.

Light absorption of the photocatalytic material as well as migration of the light-induced electrons and holes are key factors that control photocatalytic reactions. These factors are related to the electronic structural characteristics of the material [28]. Fig. 5 illustrates the light absorption properties of mixed-phase $\mathrm{MgTiO}_{3} / \mathrm{MgTi}_{2} \mathrm{O}_{5}$ microspheres that were calcined at different temperatures. The light absorption spectra of the three microspheres show that they are photo-responsive in the entire UV region. The broad absorption edge situated at about $330 \mathrm{~nm}$ indicates the optical band gap attributed to the $\mathrm{O}^{2-} \rightarrow \mathrm{Ti}^{4+}$ charge-transfer interaction. For a crystalline semiconductor, the optical absorption near the band edge follows the equation, $a h v=$ $A\left(h v-E_{\mathrm{g}}\right)^{n / 2}$, where $a, v, E_{\mathrm{g}}$ and $A$ are the absorption coef-
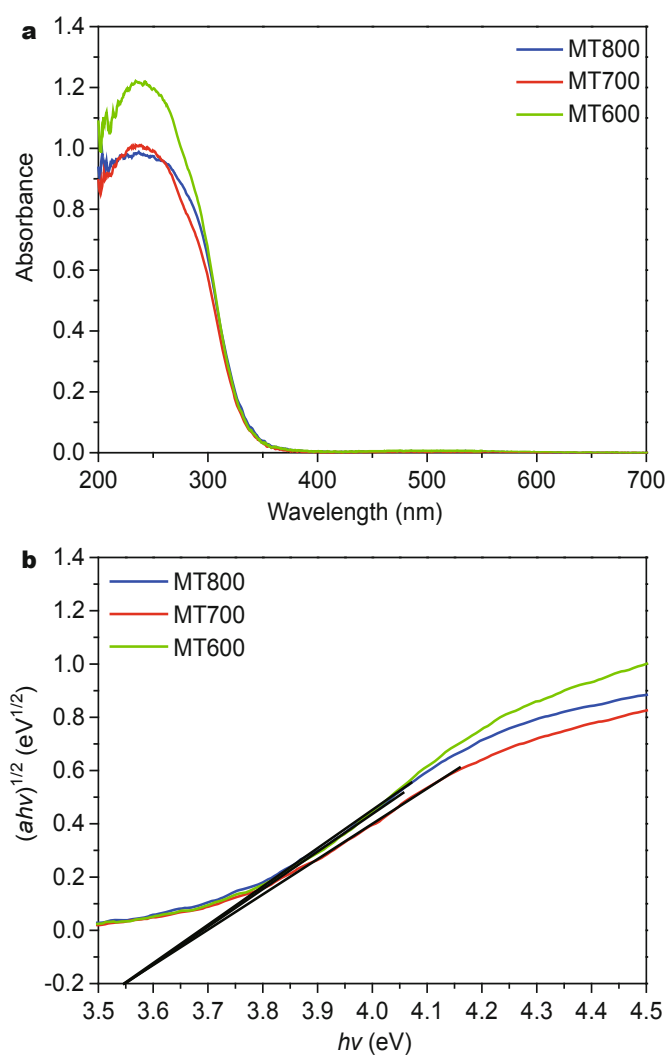

Figure 5 (a) UV-vis spectra and (b) band gaps derived from the UV-vis spectra for MT600, MT700, and MT800. ficient, light frequency, band gap, and a constant, respectively. Among these factors, the value of $n$ determines the transition characteristics in a semiconductor [29], and for $\mathrm{MgTiO}_{3} / \mathrm{MgTi}_{2} \mathrm{O}_{5}, n=4$. The band gaps of the three microspheres are calculated to be $\sim 3.55 \mathrm{eV}$ from the onset of the absorption edge, as shown in Fig. 5b. In our previous study, we demonstrated that the mixed-phase $\mathrm{MgTiO}_{3} / \mathrm{MgTi}_{2} \mathrm{O}_{5}$ has sufficient reducing capacity to reduce $\mathrm{H}^{+}$to $\mathrm{H}_{2}$ under UV light excitation.

Photocatalytic hydrogen production using semiconductors under solar irradiation has aroused interest and is regarded as a potential method for combating the energy crisis in the future [30]. The as-prepared mixed-phase $\mathrm{MgTiO}_{3} / \mathrm{MgTi}_{2} \mathrm{O}_{5}$ microspheres possess excellent charge separation and reduction capabilities, which are beneficial for photocatalytic hydrogen production. As shown in Fig. $6 a$, the hydrogen production yields are 76, 117, and 39 $\mu \mathrm{mol} \mathrm{h}{ }^{-1}$ (with $0.1 \mathrm{~g}$ of catalyst) for MT600, MT700, and MT800, respectively. The yield obtained with MT700 is approximately twice the value obtained with the mixedphase junction nanoparticles (Table S1), whereas it is four times higher than the values obtained with pure $\mathrm{MgTiO}_{3}$ and $\mathrm{MgTi}_{2} \mathrm{O}_{5}$. The time evolution of hydrogen production
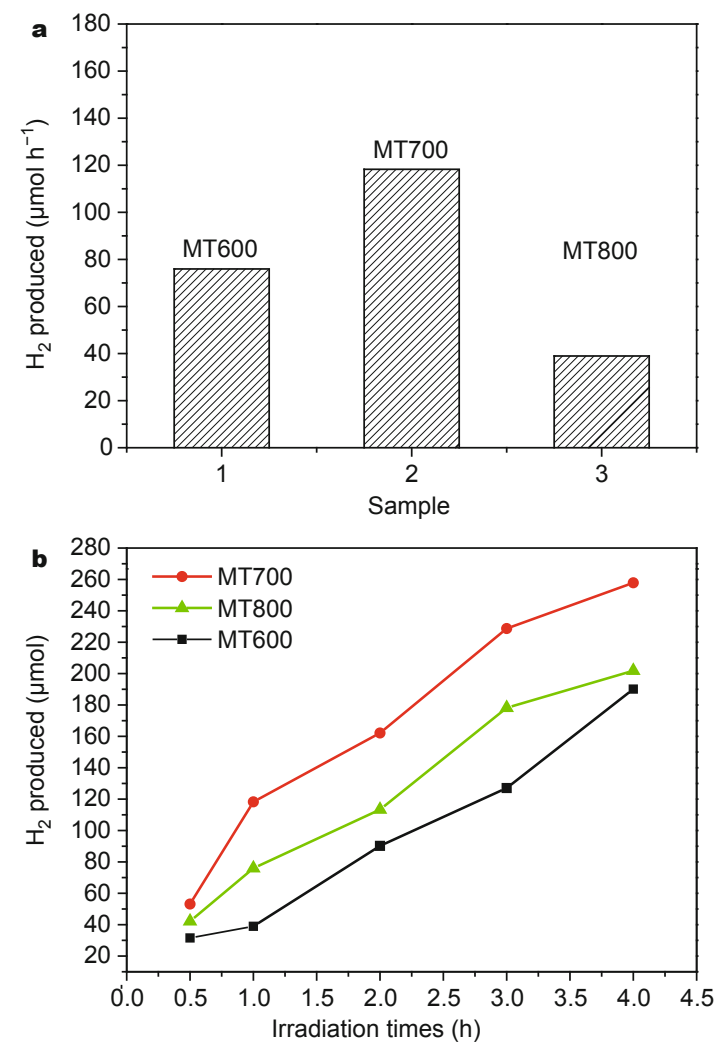

Figure 6 (a) Photocatalytic hydrogen production activities and (b) time evolution of hydrogen production of MT600, MT700, and MT800. 
shown in Fig. 6b indicates that the samples produce hydrogen continuously and stably over the course of the reaction. The AQE of MT700 is $26.9 \%$ at $313 \mathrm{~nm}$, which is consistent with the data from the UV-vis spectra. It is worth noting that the BET surface areas of MT600, MT700, and MT800 determined from the $\mathrm{N}_{2}$ adsorption-desorption isotherms shown in Fig. S3, are 22.3, 18.6, and $12.4 \mathrm{~m}^{2} \mathrm{~g}^{-1}$, respectively. This indicates that the phase transformation and surface area could influence charge transport, which in turn could affect the hydrogen production efficiency. The results of our experiments clearly indicate that the SA precursor method can be successfully used to prepare mixed-phase $\mathrm{MgTiO}_{3} / \mathrm{MgTi}_{2} \mathrm{O}_{5}$ microspheres with enhanced photocatalytic hydrogen production efficiency.

Next, we demonstrate that $\mathrm{BaTiO}_{3}, \mathrm{ZnTiO}_{3}, \mathrm{CoTiO}_{3}$, $\mathrm{NiTiO}_{3}$, and $\mathrm{CdTiO}_{3}$ microspheres can be also fabricated via this novel SA precursor method. SEM images of different resolutions, for various titanate microspheres obtained by annealing metal-SA precursors in air, are shown in Fig. 7. From the images, it is evident that the size and surface morphology of all the spheres are similar to the $\mathrm{MgTiO}_{3} /$ $\mathrm{MgTi}_{2} \mathrm{O}_{5}$ microspheres and have a diameter of about 5 $\mu \mathrm{m}$. Further, all the microspheres appear to be aggregates of small nanoparticles, as evident from the high-resolu-

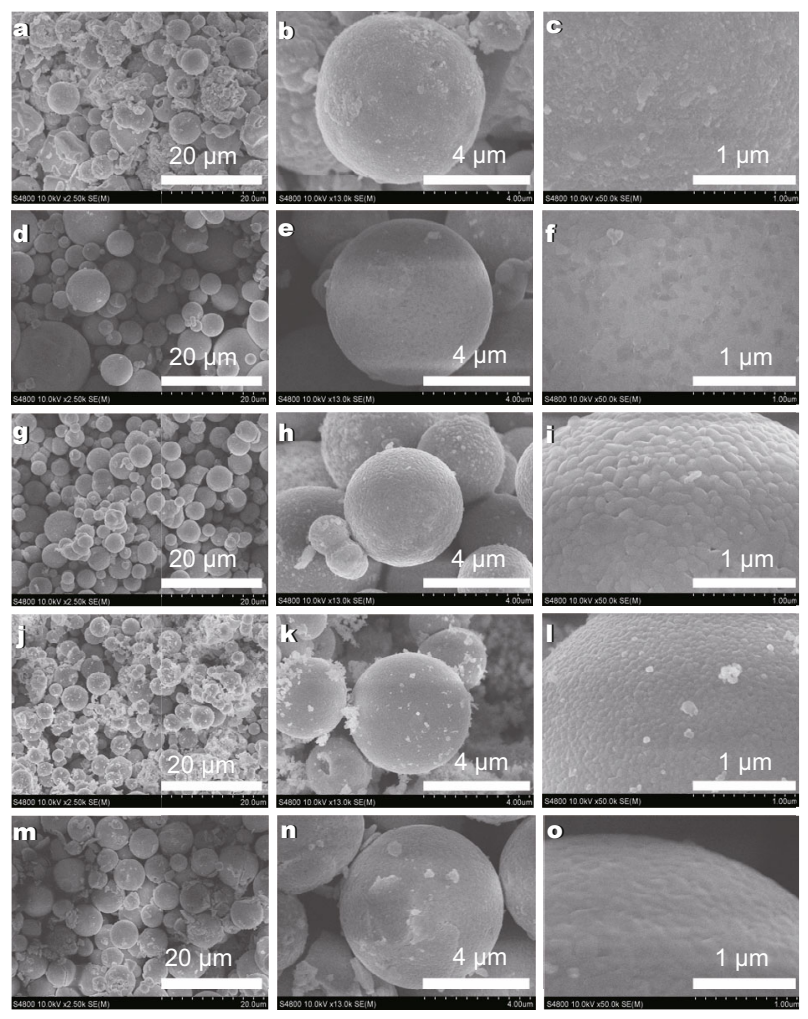

Figure 7 SEM images of various metal titanates prepared by the SA precursor method: (a, b, c) $\mathrm{BaTiO}_{3}$, (d, e, f) $\mathrm{ZnTiO}_{3}$, (g, h, i) $\mathrm{CoTiO}_{3}$, (j, $\mathrm{k}, 1) \mathrm{NiTiO}_{3}$, and $(\mathrm{m}, \mathrm{n}, \mathrm{o}) \mathrm{CdTiO}_{3}$. tion SEM images. XRD patterns of the various titanates prepared by calcination at $700^{\circ} \mathrm{C}$ for $2 \mathrm{~h}$ are shown in Fig. S4. By comparing the XRD patterns of $\mathrm{BaTiO}_{3}, \mathrm{ZnTiO}_{3}$, $\mathrm{CoTiO}_{3}, \mathrm{NiTiO}_{3}$, and $\mathrm{CdTiO}_{3}$ with the standard PDF card JCPDS no. 05-0626, 26-1500, 15-0866, 17-0617, and 290277 , respectively, it is confirmed that all the samples are in the perovskite phase. The potential applications and performance capabilities of these titanates are being investigated. We believe that the SA precursor method proposed in this study is versatile and can be used for the synthesis of various titanates with a divalent metal ion in the A site. This is a facile method with low energy consumption and is suitable for preparing high-performance titanate photocatalysts for hydrogen production and even water splitting.

In summary, we have reported a versatile and facile coordination chemistry-based process (with SA as a ligand), combined with annealing in air, for the synthesis of titanates. The annealing temperature and time are reduced significantly compared with conventional methods, owing to the soft titanate precursors. Uniform sphere-like titanates with good crystallinity and pure or mixed perovskite phase have been prepared. The mixed-phase $\mathrm{MgTiO}_{3} / \mathrm{MgTi}_{2} \mathrm{O}_{5}$ microspheres exhibit enhanced photocatalytic hydrogen production efficiencies, which are two and four times higher than those of mixed and pure-phase nanoparticles. We believe that this coordination chemistry-based soft route for preparing titanates could be extended to other perovskite functional materials, which can be utilized in energy and environmental applications.

Received 6 January, 2015; accepted 28 January, 2015 published online 10 February 2015

1 Ohtomo A, Muller DA, Grazul JL, Hwang HY. Artificial chargemodulation in atomic-scale perovskite titanates uperlattices. Nature, 2002, 419: 378-380

2 Osterloh FE. Inorganic nanostructures for photoelectrochemical and photocatalytic water splitting. Chem Soc Rev, 2013, 42: 22942320

3 MoyaX, Stern-Taulats E, Crossley S, et al. Giant electrocaloric strength in single-crystal $\mathrm{BaTiO}_{3}$. Adv Mater, 2013, 25: 1360-1365

4 Dang ZM, Yuan JK, Yao SH, Liao RJ. Flexible nanodielectric materials with high permittivity for power energy storage. Adv Mater, 2013, 25: 6334-6365

5 Bowen CR, Kim HA, Weaver PM, Dunn S. Piezoelectric and ferroelectric materials and structures for energy harvesting applications. Energy Environ Sci, 2014, 7: 25-44

6 Chu MW, Szafraniak I, Scholz R, et al. Impact of misfit dislocations on the polarization instability of epitaxial nanostructured ferroelectric perovskites. Nat Mater, 2004, 3: 87-90

7 Chung SY, Kim ID, Kang SL. Strong nonlinear current-voltage behaviour in perovskite-derivative calcium copper titanate. Nat Mater, 2004, 3: 774-778

8 Hu CC, Hsu TC, Lu SY. Effect of nitrogen doping on the microstructure and visible light photocatalysis of titanate nanotubes by a facile cohydrothermal synthesis via urea treatment. Appl Surf Sci, 2013, 280: 171-178 
9 Wang Z, Zhou L, Lou XW. Metal oxide hollow nanostructures for lithium-ion batteries. Adv Mater, 2012, 24: 1903-1911

10 Nishimura S, Abrams N, Lewis BA, et al. Standing wave enhancement of red absorbance and photocurrent in dye-sensitized titanium dioxide photoelectrodes coupled to photonic crystals. J Am Chem Soc, 2003, 125: 6306-6310

11 Fenzl C, Hirsch T, Wolfbeis OS. Photonic crystals for chemical sensing and biosensing. Angew Chem Int Ed, 2014, 53: 3318-3315

12 Ge J, Yin Y. Responsive photonic crystals. Angew Chem Int Ed, 2011, 50: 1492-1522

13 Zhang J, Sun Y, Yao Y, Huang T, Yu A. Lysine-assisted hydrothermal synthesis of hierarchically porous $\mathrm{Fe}_{2} \mathrm{O}_{3}$ microspheres as anode materials for lithium-ion batteries. J Power Sources, 2013, 222: 59-65

14 Ye M, Zheng D, Wang M, et al. Hierarchically structured microspheres for high-efficiency rutile $\mathrm{TiO}_{2}$-based dye-sensitized solar cells. ACS Appl Mater Interfaces, 2014, 6: 2893-2901

15 Miao X, Pan K, Liao Y, et al. Controlled synthesis of mesoporous anatase $\mathrm{TiO}_{2}$ microspheres as a scattering layer to enhance the photoelectrical conversion efficiency. J Mater Chem A, 2013, 1: 9853-9861

16 Higashi $\mathrm{M}$, Abe $\mathrm{R}$, Teramura $\mathrm{K}$, et al. Two step water splitting into $\mathrm{H}_{2}$ and $\mathrm{O}_{2}$ under visible light by $\mathrm{ATaO}_{2} \mathrm{~N}(\mathrm{~A}=\mathrm{Ca}, \mathrm{Sr}, \mathrm{Ba})$ and $\mathrm{WO}_{3}$ with $\mathrm{IO}_{3}^{-} / \mathrm{I}^{-}$shuttle redox mediator. Chem Phys Lett, 2008, 452: $120-123$

17 Higashi M, Domen K, Abe R. Fabrication of an efficient $\mathrm{BaTaO}_{2} \mathrm{~N}$ photoanode harvesting a wide range of visible light for water splitting. J Am Chem Soc, 2013, 135: 10238-10241

18 Qu Y, Zhou W, Jiang L, Fu HG. Porous cobalt titanate nanorod: new candidate for visible light-driven photocatalytic water oxidation. ChemCatChem, 2014, 6: 265-270

19 Qu Y, Zhou W, Ren Z, et al. Facile preparation of porous $\mathrm{NiTiO}_{3}$ nanorods with enhanced visible-light-driven photocatalytic performance. J Mater Chem, 2012, 22: 16471-16476

$20 \mathrm{Qu} \mathrm{Y}$, Zhou W, Ren ZY, et al. Facile synthesis of porous $\mathrm{Zn}_{2} \mathrm{Ti}_{3} \mathrm{O}_{8}$ nanorods for photocatalytic overall water splitting. ChemCatChem, 2014, 6: 2258-2262

21 Libri S, Mahler M, Espallargas GM, et al. Ligand substitution within nonporous crystals of a coordination polymer: elimination from and insertion into Ag-O bonds by alcohol molecules in a solidvapor reaction. Angew Chem Int Ed, 2008, 47: 1693-1697
$22 \mathrm{Qu}$ Y, Zhou W, Xie Y, et al. A novel phase-mixed $\mathrm{MgTiO}_{3}-\mathrm{MgTi}_{2} \mathrm{O}_{5}$ heterogeneous nanorod for high efficiency photocatalytic hydrogen production. Chem Comm, 2013, 49: 8510-8512

23 Ran J, Zhang J, Yu J, Jaroniec M, Qiao SZ. Earth-abundant cocatalysts for semiconductor based photocatalytic water splitting.ChemSoc Rev, 2014, 43: 7787-7812

24 Jiang X, Wang Y, Herricks T, Xia YN. Ethylene glycol-mediated synthesis of metal oxide nanowires. J Mater Chem, 2004, 14: 695-703

25 Chow EHH, Strobridge FC, Friščić T. Mechanochemistry of magnesium oxide revisited: facile derivatisation of pharmaceuticals using coordination and supramolecular chemistry. Chem Commun, 2010, 46: 6368-6370

26 Hawxwell SM, Adams H, Brammer L. Two-dimensional metalorganic frameworks containing linear dicarboxylates. Acta Crystallogr B-Struct Sci, 2006, 62: 808-814

27 Coker EN, Boyle TJ, Rodriguez MA, Alam TM. Structurally characterized magnesium carboxylates with tuned melting points. Polyhedron, 2004, 23: 1739-1747

28 Jing LQ, Zhou W, Tian GH, Fu HG. Surface tuning for oxide-based nanomaterials as efficient photocatalysts. Chem Soc Rev, 2013, 42: 9509-9549

29 Lin XP, Xing JC, Wang WD, et al. Photocatalytic activities of heterojunction semiconductors $\mathrm{Bi}_{2} \mathrm{O}_{3} / \mathrm{BaTiO}_{3}$ : a strategy for the design of efficient combined photocatalysts. J Phys Chem C, 2007, 111: 18288-18293

30 Chen X, Shen S, Guo L, Mao SS. Semiconductor-based photocatalytic hydrogen generation. Chem Rev, 2010, 110: 6503-6570

Acknowledgements This work was supported by the National Natural Science Foundation of China (21031001, 91122018, 21371053 and 21376065), the Cultivation Fund of the Key Scientific and Technical Innovation Project, Ministry of Education of China (708029).

Author contributions $\mathrm{Fu} \mathrm{H}$ designed and engineered this work. Liu W performed the experiments on the titanates. Qu Y and Liu W wrote this paper. All authors contributed to general discussion.

Conflict of interest The authors declare that they have no conflict of interest.

Supplementary information Supporting data are available in the online version of the paper. 


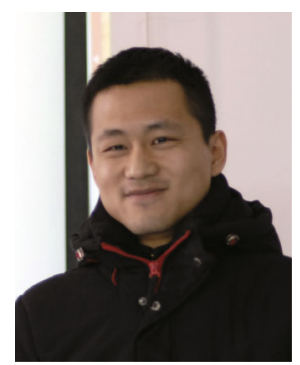

Wei Liu obtained his bachelor's degree from Heilongjiang University in 2014. He then joined Professor Honggang Fu's research group for his master studies, mainly working on design and synthesis of titanates based photocatalytic materials, photocatalytic hydrogen production and $\mathrm{CO}_{2}$ reduction.

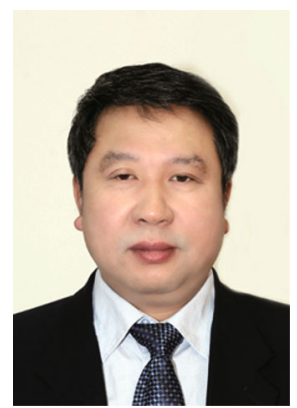

Honggang Fu received his BSc in 1984 and MSc in 1987 from Jilin University. Subsequently, he joined Heilongjiang University as an assistant professor. In 1999, he received his PhD degree from Harbin Institute of Technology and became a full professor in 2000. Currently, he is a Cheung Kong Scholar Professor. His interests are in the areas of oxide-based semiconductor nanomaterials for solar energy conversion and photocatalysis, and crystalline carbon-based nanomaterials for energy conversion and storage, including design, synthesis, and the study of physical and chemical properties of these materials. So far, he has published over 260 SCI papersas corresponding author with over 4500 citations. Among them, 12 papers are in the ESI Top 1\%.

中文摘要 本文报道了一种简单通用的水杨酸前驱体路线合成铁酸盐微球的方法, 水杨酸作为配体和结构导向剂诱导前驱体形成球形结 构. 利用水杨酸与乙酸镁和钛酸四丁酯的配位作用, 进而通过溶剂热反应得到镁-钛-水杨酸前驱体微球, 在空气下焙烧得到混相 $\mathrm{MgTiO}_{3} /$ $\mathrm{MgTi}_{2} \mathrm{O}_{5}$ 微球. 由于其合适的能带位置和混相结, 混相 $\mathrm{MgTiO}_{3} / \mathrm{MgTi}_{2} \mathrm{O}_{5}$ 微球表现出了优异的光催化产氢性能, 相比混相 $\mathrm{MgTiO}_{3} / \mathrm{MgTi}_{2} \mathrm{O}_{5}$ 纳米粒子和纯相纳米粒子产氢性能分别高出 2 和 4 倍. 同时, 这种配位前驱体路线可以拓展合成多种二价金属钛酸盐微球, 并用此方法成功 制备了 $\mathrm{BaTiO}_{3}, \mathrm{ZnTiO}_{3}, \mathrm{CoTiO}_{3}, \mathrm{NiTiO}_{3}$ 和 $\mathrm{CdTiO}_{3}$ 微球. 这种基于配位化学路线的合成方法对于钛酸盐(或钙钛矿、尖晶石等)等功能微球 材料的低温制备具有较高的科学意义和应用价值. 